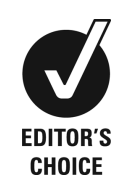

${ }^{1}$ Department of Haematology, Stoke Mandeville Hospital, Aylesbury, UK

${ }^{2}$ Department of Haematology, Churchill Hospital, Oxford, UK

\section{Correspondence to} Dr Helen Elizabeth Jane Tyrrell, helen_ej_tyrrell@yahoo.com

Accepted 20 December 2014

\title{
A rare but potentially fatal cause of diarrhoea and weight loss: enteropathy-associated T-cell lymphoma
}

\author{
Gorav Neel Wali, ${ }^{1}$ Helen Elizabeth Jane Tyrrell, ${ }^{1}$ Graham P Collins, ${ }^{2}$ Helen J Eagleton ${ }^{1}$
}

\section{SUMMARY}

Enteropathy-associated T-cell lymphoma (EATL) is a rare but potentially fatal cause of diarrhoea and weight loss. EATL commonly presents with abdominal pain, diarrhoea and weight loss, but can also present with complications such as bowel obstruction and perforation. It is a tumour of intraepithelial lymphocytes that occurs in a relatively young population. It is the most common neoplastic complication of coeliac disease, but can occur with no prior diagnosis of coeliac disease. This case demonstrates the difficulties that can be faced in diagnosing this disorder, particularly when there is no preceding history of coeliac disease. Early diagnosis is of utmost importance in order to start treatment before the effects of malnutrition increase the risk of complications from chemotherapy. Hence awareness of the condition among general medical physicians, to whom it will often present first, is essential. However, even with prompt diagnosis, outcomes for this condition remain poor.

\section{BACKGROUND}

Diarrhoea and weight loss are relatively common presenting symptoms on the medical take, with a broad differential diagnosis. Enteropathy-associated T-cell lymphoma (EATL) is a very rare cause of these symptoms, so can be overlooked by the general medical team, and its diagnosis is challenging. Although it has a very poor prognosis, it occurs in a relatively young population and there are treatments available if diagnosis is made before severe malnutrition increases the risk of complications from chemotherapy. It is a fatal complication of coeliac disease, and should be considered in those with refractory coeliac disease. Here we present a difficult case to raise awareness of this condition in the general medical community.

\section{CASE PRESENTATION}

A 47-year-old Caucasian man with no medical history presented on the acute medical take with diarrhoea and weight loss. He reported a 6-week history of profuse, smelly, watery diarrhoea that was difficult to flush away. This was associated with abdominal pain, bloating, fatigue and a reduced appetite. Over the preceding few days he had developed night sweats, and noticed ankle swelling with mild dyspnoea. From onset of symptoms he had lost $16 \mathrm{~kg}$ in weight. On examination he was noted to be febrile at $38^{\circ} \mathrm{C}$, tachycardic and cachectic. His abdomen was distended, with generalised tenderness and shifting dullness. A blanching maculopapular rash on his back was noted. For a list of differential diagnosis at this point, see box 1 .
Laboratory examination showed raised inflammatory markers (white cell count $13.6 \times 10^{9} / \mathrm{L}$; C reactive protein $129 \mathrm{mg} / \mathrm{L}$ ) with hypoalbuminaemia $(14 \mathrm{~g} / \mathrm{L})$. ECG showed sinus tachycardia. A coeliac screen testing for anti-transglutaminase antibodies, HIV serology, tumour markers carcino embryonic antigen and Ca19-9, antinuclear antibody and serum electrophoresis were all negative. Lactate dehydrogenase was normal. Stool samples for faecal elastase and $\alpha 1$ antitrypsin showed no abnormality. Blood and stool cultures were negative.

A CT scan of the chest, abdomen and pelvis revealed gross ascites, retroperitoneal and central mesenteric lymphadenopathy and small bilateral pleural effusions (figure 1). Unfortunately, none of the lymph nodes were amenable to radiologicalguided biopsy. An ascitic drain was inserted, but little fluid was drained. The ascitic fluid was negative for both malignant cells and on culture. Oesophagogastroduodenoscopy demonstrated only oesophagitis, but the pylorus could not be passed as the patient was uncomfortable lying flat, therefore preventing fluid aspiration or biopsies from the small bowel.

Despite broad spectrum antibiotic therapy the patient continued to decline with further weight loss, abdominal distension and high temperatures. He was started on parenteral nutrition in order to improve nutritional status in preparation for laparotomy for lymph node sampling. Numerous ascitic drains were inserted during this time returning only small amounts of fluid. He then became obstructed, vomiting bilious fluid, for which a Ryles tube was inserted and a day later he developed signs of

Box 1 Differential diagnosis of diarrhoea and malabsorption

Differential diagnosis of diarrhoea and malabsorption (not exhaustive):

- Infections-viral gastroenteritis (norovirus, rotavirus), bacterial infection (Escherichia coli, Campylobacter, Shigella), giardiasis, Whipple's disease and HIV

- Inflammatory bowel disease

- Malignancy-solid tumours, carcinoid, lymphoma

- Coeliac disease

- Small bowel bacterial overgrowth

- Pancreatic insufficiency

- Zollinger-Ellison syndrome 


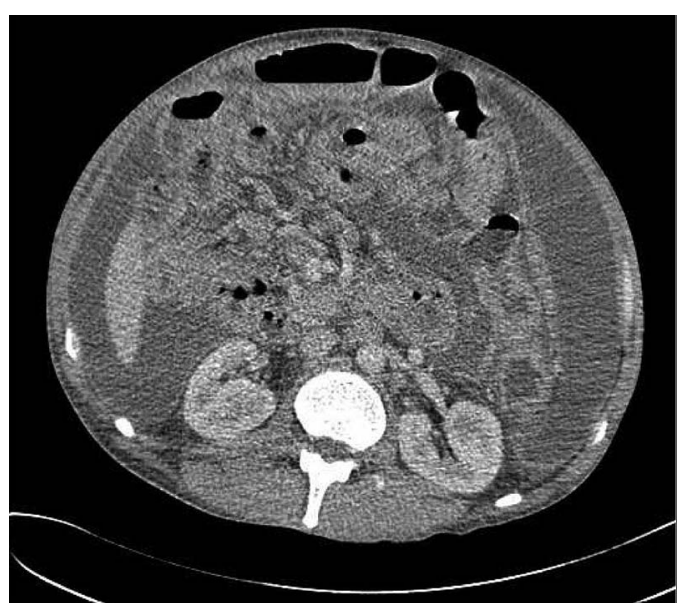

Figure $1 \mathrm{CT}$ with contrast axial slice demonstrating retroperitoneal lymph nodes, bowel wall thickening and ascites.

peritonism and dark green fluid started draining from the ascitic drain. Therefore, he underwent emergency laparotomy.

Laparotomy confirmed perforated bowel. The bowel was found to be matted together and oedematous, making it difficult to determine exactly which section of small bowel was affected. A wedge resection and jejunostomy were performed. The abdomen was left open with a vacuum-assisted-closure dressing to be closed later.

Histology demonstrated bowel wall thickening, with extensive surface ulceration and perforation. There was a dense transmural infiltration with atypical lymphoid cells, with associated shortening of the villi (figures 2 and 3). These cells were also seen in the mesentery and lymph nodes. Immunostaining of the lymphoid cells were positive for CD3, CD8 and CD56, but negative for CD4 and CD20 (figure 4). The Ki67 stain showed that $50 \%$ of the cells were in proliferation. The diagnosis was therefore a high-grade T-cell Non-Hodgkin's lymphoma of the small bowel: EATL. The presence of CD8 and CD56 suggested this was type II EATL, which is less commonly associated with coeliac disease, but also much rarer.

\section{TREATMENT}

On day 18 of his admission the patient was started on CHOP chemotherapy regimen (cyclophosphamide, doxorubicin, vincristine and dexamethasone) and a second cycle was given

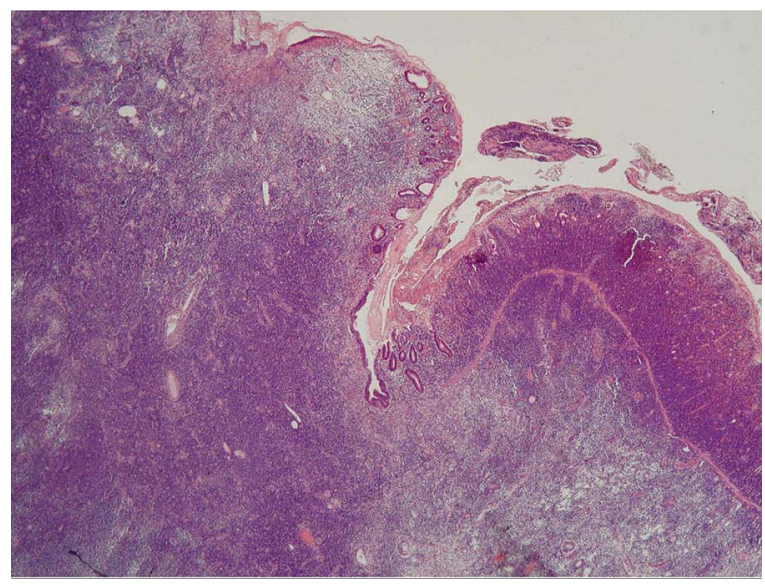

Figure 2 Low power image of the small bowel with almost complete loss of villi and a dense transmural lymphoid infiltrate.
16 days after the first. The decision to treat with CHOP chemotherapy was made after discussion at the regional lymphoma multidisciplinary team meeting, who advised a regime of four cycles of CHOP, followed by two cycles of Ifosfamide, Carboplatin and Etoposide (ICE), then autologous stem cell transplantation.

\section{OUTCOME AND FOLLOW-UP}

However, he underwent steady deterioration, continuing to have high fevers and had multiple courses of antibiotics. An intra-abdominal collection was demonstrated on CT, which was not amenable to surgery or percutaneous drainage, so treated conservatively. He next developed large, bilateral pleural effusions and liver failure. He was transferred back to intensive care, but it was eventually decided that he was not fit for further chemotherapy and that palliative treatment would be more appropriate. He unfortunately passed away the day after this decision. Cytology from pleural aspiration subsequently demonstrated a heavy lymphoid infiltrate consistent with lymphoma, suggesting that the disease was progressing despite chemotherapy.

\section{DISCUSSION}

EATL is a rare tumour of intraepithelial lymphocytes with an incidence of $0.14 / 100000$ per year in the UK. ${ }^{1}$ It is the most common neoplastic complication of coeliac disease, seen with greater frequency in Northern Europe where coeliac disease is more prevalent ${ }^{2} 2-3 \%$ of coeliac disease sufferers develop intestinal lymphoma, and of these $65 \%$ have a T-cell immunophenotype. ${ }^{3}$

EATL frequently presents with a recurrence of malabsorption in patients with a history of coeliac disease, accompanied by abdominal pain. ${ }^{4}$ However, it can also occur in patients with no prior history of coeliac disease, ${ }^{4}$ as in this case, making diagnosis more difficult. The most common presenting symptoms are abdominal pain, weight loss and diarrhoea. Patients may also present with complications such as small bowel perforation or obstruction. ${ }^{5}$ Factors that may suggest the possibility of this condition are associated 'B symptoms': fever, sweats and extreme weight loss, more than would be expected simply due to diarrhoea; and the persistence of symptoms with rapid clinical deterioration of the patient. However, often the diagnosis will only be reached after exclusion of other causes. In patients with these symptoms who are becoming rapidly more unwell, an aggressive diagnostic approach is needed with early laparotomy.

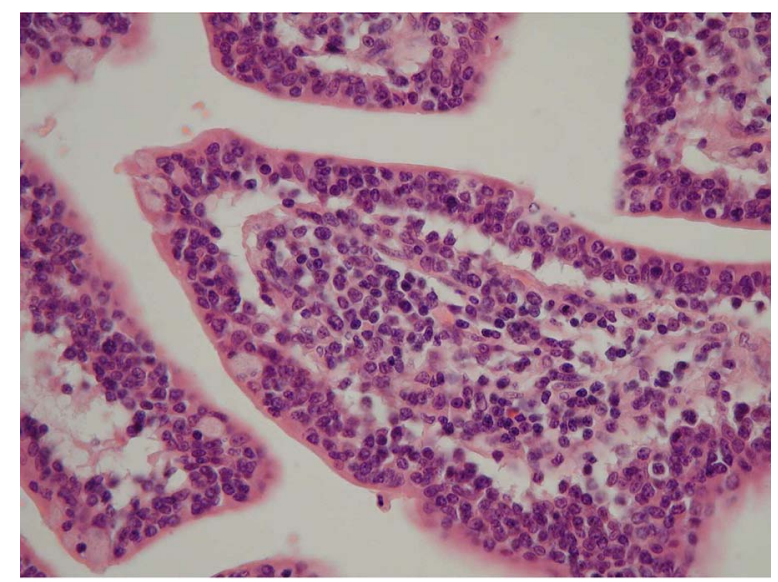

Figure 3 High power image of the relatively preserved mucosa with marked intraepithelial lymphocytosis. 


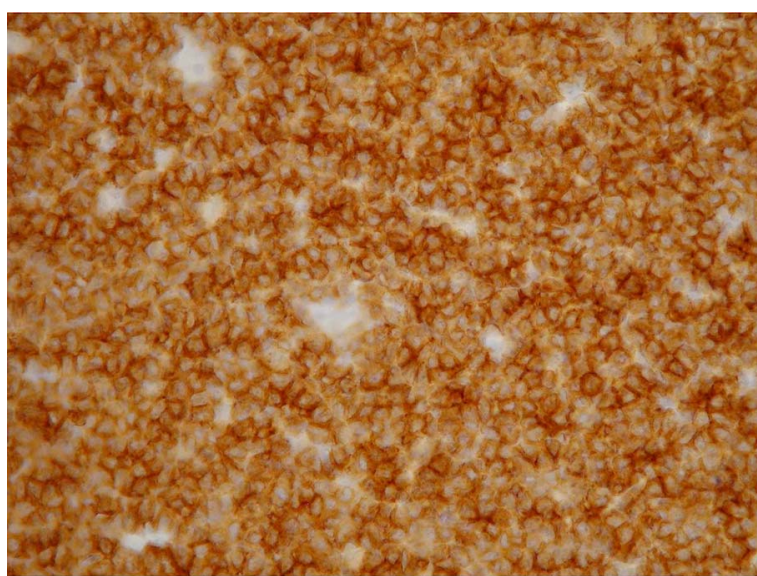

Figure 4 Immunostain of CD3, a T-lineage marker showing diffuse strong positivity in the lymphoid infiltrate.

Refractory coeliac disease, which may precede EATL, demonstrates markedly raised numbers of intraepithelial lymphocytes, and it is postulated that from these EATL arises. ${ }^{67}$ There are two types of refractory coeliac disease. In refractory coeliac disease type 1 , the intraepithelial lymphocytes are of a normal phenotype, while in refractory coeliac disease type 2 there is clonal expansion of an aberrant intraepithelial lymphocyte phenotype. ${ }^{8}$ Type 2 has a $60-80 \%$ risk of developing EATL within 5 years, ${ }^{57}$ and therefore some have proposed chemotherapy and autologous stem cell transplantation even at this stage. ${ }^{9}$

Diagnosis of EATL is made from bowel histology, often at laparotomy, which demonstrates ulcerating mucosal masses involving the intestinal walls. ${ }^{10}$ It most frequently involves the jejunum or ileum. Biopsy of the lesion demonstrates large lymphoid cells associated with necrosis and an inflammatory background, including large numbers of eosinophils and histiocytes. $^{2}$ The adjacent small intestine mucosa demonstrates villous atrophy, crypt hyperplasia and intraepithelial lymphocytosis. ${ }^{2}$ However, histology has been shown to be variable. ${ }^{5}$

EATL is divided into two distinct subtypes. Type I EATL is more common than type II, particularly in Europe; in one series it was found in $66 \%$ of cases worldwide and $79 \%$ of cases diagnosed in Europe. ${ }^{11}$ While both types are associated with coeliac disease, this association is much greater in type I EATL and there is also a stronger associated with HLA-DQ2 and $8 .{ }^{11}$ The two subtypes are morphologically different: EATL type I is characterised by large anaplastic cells or medium to large cells with irregular nuclear contours and variable amounts of cytoplasm, in EATL type II there are small to medium sized cells with round, hyperchromatic nuclei with a stippled chromatin pattern. ${ }^{11}$ EATL type I lymphoma cells usually express CD30, whereas CD56 is seen more commonly on EATL type II lymphoma cells. Both commonly express CD8 and are usually negative for CD4. ${ }^{11}$ The two diseases are also linked to different genetic abnormalities; in type I EATL gains of $9 \mathrm{q} 31.3$ and deletions of $16 \mathrm{q} 12.1$ are seen, whereas gains of $8 \mathrm{q} 24,1 \mathrm{q}$ and $5 \mathrm{q}$ are more often found in type II EATL. ${ }^{11}$

EATL type 1 has a tendency to present with coeliac disease-related symptoms of malabsorption and weight loss, whereas EATL type 2 often presents with obstruction or perforation of the small bowel. ${ }^{12}{ }^{13}$ However, the International Peripheral T-Cell Lymphoma Project showed no significant difference between the presentation of the two conditions, except that in type II the tumours tend to be slightly bigger, suggesting that clinical presentation alone cannot be used to differentiate between the two. ${ }^{11}$ There are no differences in the way that these two tumours are currently treated and there is no survival difference between type I and type II EATL. ${ }^{11}$

Outcomes for EATL are poor. Owing to the malabsorption, patients are often malnourished, and do not tolerate treatment well, with death frequently occurring due to perforation and gastrointestinal bleeding. ${ }^{5} 14$ The rarity of the disease precludes accurate figures for prognosis, but case series report median progression free survival of 3-4 months and median overall survival of 7 months. ${ }^{1}$ The International T-cell Lymphoma Project identified 62 patients with EATL, with an overall 5-year survival of $20 \%$. $^{15}$

There is currently no agreed consensus for the treatment of EATL, due to its rarity and corresponding lack of trials. The usual lymphoma treatment of CHOP chemotherapy produces a response in $50 \%$ or more, but long-term survival in no more than $10 \%{ }^{16}$ Most centres use CHOP or a similar, anthracycline-based regimen. There was a single centre cohort study that suggested an alternative regime, of ifosfamide, vincristine, etoposide and methotrexate (IVE/MTX), was superior to anthracycline-based regimens. ${ }^{1}$ While their results appear impressive, this study had some limitations. They were comparing anthracycline-based regimens given without subsequent stem cell transplantation over the time period 1994 1998, with the IVE/MTX regimen followed by autologous stem cell transplantation from 1998 onwards. ${ }^{1}$ Therefore, it is difficult to distinguish to what extent the improved progression free survival and overall survival were due to the addition of autologous stem cell transplantation, rather than the novel chemotherapy. There could also have been improvements in other areas of patient care, such as surgical techniques, patient selection for chemotherapy or management of complications of chemotherapy, over the 15-year period this study spanned.

High-dose chemotherapy with autologous stem cell transplantation has been trialled in a few cases with conflicting results. ${ }^{1}{ }^{17}$

19 A small study of six patients demonstrated promising results with four patients remaining alive and in complete remission at 1.83-4.32 years, ${ }^{10}$ however, another study of four patients showed disappointing outcomes with three of the four patients dying from relapse within a few months of transplant. Studies of allogenic stem cell transplant in relapsed and refractory aggressive non-Hodgkin lymphoma suggest that it could have a role in treatment, although it is unclear whether this could be extrapolated to EATL. ${ }^{2021}$ Some authors have also suggested that newer therapies such as monoclonal antibodies and apoptosis inducing small molecules may be used to treat EATL in the future, and there has been success in individual cases. ${ }^{12} 22$ There appears to be a very limited role for surgery and radiotherapy, to be used for debulking and resection of masses with high risk of obstruction, based on clinical judgement. ${ }^{2}$ Further studies are needed to determine the best management for EATL, as currently the evidence is lacking and conflicting.

\section{Learning points}

Enteropathy-associated T-cell lymphoma (EATL) commonly presents with abdominal pain, diarrhoea and weight loss.

- EATL is the most common neoplastic complication of coeliac disease but can occur with no prior history of this.

- Early diagnosis is important to allow treatment before malnutrition increases the risk of complications from chemotherapy.

EATL is associated with poor outcomes even with treatment. 


\section{Competing interests None.}

\section{Patient consent Obtained.}

Provenance and peer review Not commissioned; externally peer reviewed.

\section{REFERENCES}

1 Sieniawski M, Angamuthu M, Boyd K, et al. Evaluation of enteropathy associated T-cell lymphoma comparing standard therapies with a novel regimen including autologous stem cell transplantation. Blood 2010;115:3664-70.

2 Ferreri AJ, Zinzani PL, Govi S, et al. Enteropathy-associated T-cell lymphoma. Crit Rev Oncol Hematol 2011;79:84-90.

3 Catassi C, Bearzi I, Holmes GK. Association of celiac disease and intestinal lymphomas and other cancers. Gastroenterology 2005;128:579-86.

4 Isaac PG, Du MQ. Gastrointestinal lymphoma: where morphology meets molecular biology. J Pathol 2005;205:255-74.

5 Gale J, Simmonds PD, Mead GM, et al. Enteropathy-type intestinal T-cell lymphoma: clinical features and treatment of 31 patients in a single center. J Clin Onc 2000:18:795-803.

6 Wahab PJ, Meijer JW, Goerres MS, et al. Coeliac disease: changing views on gluten-sensitive enteropathy. Scand I Gastroenterol Supp/ 2002;236:60-5

7 Cellier C, Delabesse E, Helmer C, et al. Refractory sprue, coeliac disease, and enteropathy-associated T-cell lymphoma. Lancet 2000;356:203-8.

8 Green PH, Cellier C. Celiac disease. N Engl I Med 2007;357:1731-43.

9 Al-Toma A, Visser OJ, van Roessel HM, et al. Autologous hematopoietic stem cell transplantation in refractory celiac disease with aberrant T cells. Blood 2007;109:2243-9.

10 Bishton MJ, Haynes AP. Combination chemotherapy followed by autologous stem cell transplant for enteropathy-associated T cell lymphoma. Br I Haematol 2006;136:111-13.

11 Delabie J, Holte H, Vose JM, et al. Enteropathy-associated T-cell lymphoma: clinical and histological findings from the international peripheral T-Cell lymphoma project. Blood 2011:118:148-55.
12 Van de Water JM, Cillessen SA, Visser OJ, et al. Enteropathy associated T-cell lymphoma and its precursor lesions. Best Pract Res Clin Gastroenterol 2010;24:43-56.

13 Al-Toma A, Verbeek WH, Hadithi M, et al. Survival in refractory coeliac disease and enteropathy-associated T-cell lymphoma: retrospective evaluation of single-centre experience. Gut 2007;56:1373-8.

14 Daum S, Ullrich R, Heise W, et al. Intestinal non-Hodgkins lymphoma: a multicentre prospective clinical study from the German Study Group on Intestinal non-Hodgkins lymphoma. J Clin Oncol 2003;21:2740-6.

15 Vose J, Armitage J, Weisenburger D, et al. International peripheral T-cell and natural killer/T-cell lymphoma study: pathology findings and clinical outcomes. I Clin Oncol 2008;26:4124-30.

16 Dearden $C E$, Johnson R, Pettengell R, et al. Guidelines for the management of mature T-cell and NK-cell neoplasms (excluding cutaneous T-cell lymphoma). $\mathrm{Br} J$ Haematol 2011:153:451-85.

17 Okuda M, Nomura J, Tateno H, et al. CD56 positive intestinal T-cell lymphoma: treatment with high dose chemotherapy and autologous peripheral blood stem cell transplantation. Intern Med 2002;41:734-7.

18 Al-Toma A, Verbeek WH, Visser OJ, et al. Disappointing outcome of autologous stem cell transplantation for enteropathy-associated T-cell lymphoma. Dig Liver Dis 2007;39:634-41

19 Rongey C, Micallef I, Smyrk T, et al. Successful treatment of enteropathy-associated T-cell lymphoma. Dig Dis Sci 2006;51:1082-6.

20 Hosing C, Saliba RM, McLaughlin P, et al. Long-term results favor allogenic over autologous hematopoietic stem cell transplantation in patients with refractory or recurrent indolent non-Hodgkin's lymphoma. Ann Oncol 2003;14: 737-44.

21 Doocey RT, Toze CL, Connors JM, et al. Allogenic haematopoietic stem-cell transplantation for relapsed and refractory aggressive histology non-Hodgkin lymphoma. Br J Haematol 2005;131:223-30.

22 Khalaf WF, Caldwell ME, Reddy N. Brentuximab in the treatment of CD30-positive enteropathy-associated T-cell lymphoma. J Natl Compr Canc Netw 2013;11:137-40.

Copyright 2015 BMJ Publishing Group. All rights reserved. For permission to reuse any of this content visit

http://group.bmj.com/group/rights-licensing/permissions.

BMJ Case Report Fellows may re-use this article for personal use and teaching without any further permission.

Become a Fellow of BMJ Case Reports today and you can:

- Submit as many cases as you like

- Enjoy fast sympathetic peer review and rapid publication of accepted articles

- Access all the published articles

- Re-use any of the published material for personal use and teaching without further permission

For information on Institutional Fellowships contact consortiasales@bmjgroup.com

Visit casereports.bmj.com for more articles like this and to become a Fellow 